\title{
The Interrelation of Circulation Processes in the Atmosphere by B.L. Dzerdzeyevskiy with the Change of Runoff in the Basins of Rivers of Central Asia
}

\author{
Aisulu Tursunova \\ Institute of Geography, Almaty, Kazakhstan \\ Email: ais.tursun@bk.ru \\ Received 4 September 2014; revised 18 October 2014; accepted 20 November 2014 \\ Copyright (C) 2014 by author and OALib. \\ This work is licensed under the Creative Commons Attribution International License (CC BY). \\ http://creativecommons.org/licenses/by/4.0/ \\ (c) (i) Open Access
}

\begin{abstract}
The article contains analysis of the interrelation of circulation processes in the atmosphere with the change of runoff in the basins of rivers. The results of estimates which show the relationship of circulation processes in the atmosphere with the runoff of the zone of formation of Central Asia of one of southern regions are discussed. The typification of circulation processes by B.L. Dzerdzeyevskiy and previously made estimates of water resources in the basins of rivers of South Kazakhstan were assumed as a basis. The certain areas were considered in this work: the Ile-Balkash basin, basin of river Shu-Talas and basin of the Syrdariya river; each basin is considered separately; since the runoff varies by regions and by the value of fluctuations, it is not permanent, because of the various factors of runoff formation in individual basins of that region. The calculations performed have shown the possibility of using typification of elementary circulation mechanism (ECM) for further researches of climatic changes, including determining the direction of change of river runoff in other river basins. The created database on annual values of each of the 41 types of ECM can be used in other studies as well.
\end{abstract}

\section{Keywords}

Typification of Circulation of the Atmosphere by B.L. Dzerdzeyevskiy, Elementary Circulation Mechanism (ECM), Water Resources, The Basin of River of South Kazakhstan

Subject Areas: Environmental Sciences, Hydrology

\section{Introduction}

The cyclonic and anticyclonic activity of the atmosphere is the main factor determining the state and changea-

How to cite this paper: Tursunova, A. (2014) The Interrelation of Circulation Processes in the Atmosphere by B.L. Dzerdzeyevskiy with the Change of Runoff in the Basins of Rivers of Central Asia. Open Access Library Journal, 1: e1080. http://dx.doi.org/10.4236/oalib.1101080 
bility of weather on the Earth. Circulation factors are the most dynamic, which cause transfer of large masses of atmospheric air formed over world oceans and land, as well as between certain climatic zones of the Earth. There are a number of typifications of circulation processes and methods of their estimation, suggested by G.Ya. Vangengeim, A.A. Girs, M.Kh. Baidal and others at various times.

Typification of circulation of the atmosphere of the northern hemisphere by B.L. Dzedzeyevskiy was made on the basis of synoptic analysis of weather maps and baric topography of the northern hemisphere and considered the number and geographical location of the Arctic invasions (blocking processes) and outlets of southern cyclones. The presence of dynamic schemes of each elementary circulation mechanism, in short ECM, allows determining what the synoptic situation is at each point of the northern hemisphere at this or another type of ECM [1]-[4].

In the typification of B.L. Dzerdzeyevskiy the terms "zonal" and "meridional" are used. Meridional are northern (movement of arctic anticyclones and distribution of their ridges to the south) and southern (movement of cyclones from low to high latitudes). Terms "latitudinal" and "longitudinal" are the analogs of these terms in relation to the sectors of the hemisphere and their parts, i.e. all types of ECM, depending on the distribution are subdivided into respective groups.

Typification of B.L. Dzerdzeyevskiy was developed in the interiors of the hydrometeorological service; the first work was published in the proceedings of the research institutions of the hydrometeorological service in 1946; since 1955 the typification has been developed in the Institute of Geography of the RAS [5]-[7]. According to this method, all the variety of circulation processes in the atmosphere of the Northern Hemisphere is divided into a finite number of ECM-elementary circulation mechanisms (total 41 types). ECM annually repeats itself and alternates in a certain sequence due to seasonal weather changes. A calendar of ECM types is published (calendar of the consistent change of ECM, 1987), i.e. tables, according to which it is possible to estimate the frequency of repeatability of a particular type of ECM (in days) for each year. As a result, it is possible to obtain multi-year series of duration of the selected type of ECM, which can be analyzed using statistical methods that are usual for hydrologists and compare them with similar characteristics of river runoff. As we can see, the typification of ECM by B.L. Dzerdzeyevskiy allows obtaining quantitative descriptions of atmosphere circulation, which advantageously distinguish it from the above mentioned existing methods of typification.

\section{Special Studies on Testing of ECM}

Special studies on testing of ECM, which were performed by B.L. Dzerdzeyevskiy and researches from the Department of Climatology of the IG of the RAS and other independent specialists showed high effectiveness of using the proposed typification to describe quite a number of natural phenomena and the establishment of sufficiently reliable quantitative relationships between the components of the climate system (CCS). In the course of long-term works, performed by various researches, extensive materials, which are partly placed on the site [8], have been compiled; the original scientific results were obtained (list of scientific publications of 517 titles is placed on the same site).

On the territory of Kazakhstan, the typification of circulation processes by B.L. Dzerdzeyevskiy was used in the works of Akhmetova G.S. to identify their role in the change of air temperature over the Northern Hemisphere for the period from 1899 to 1987 [9]; L.A. Eriskovskaya evaluated the influence of synoptic processes on the regime of precipitation and the changes in the mass balance of the Tuyyksu glacier [10]. Also studies on the theoretical generalization and assessment of the reactions of the rivers runoffs to change in the course of ECM by B.L. Dzerdzeyevskiy in some river basins of Kazakhstan were carried out by us [11]. Previously, an independent analysis of the course of all 41 types of ECM was conducted and some peculiarities of changes of them in recent years, were identified, which are reflected in the works in detail [12]-[15].

Out of the researches [16] it follows that in the meridional group the meridional northern processes are currently rising, and the meridional southern ones are decreasing in duration. Figure 1 shows an obvious representation of the course of meridional and zonal groups of ECM [8].

Also a number of conclusions, which formed the basis of selection of runoff forming ECM was made by the authors of the research [16] [17]: 1) from 1986 to 1997 the duration of northern and southern meridional groups of circulation was approximately at the same level and significantly exceeded the duration of other groups, and southern meridional group was more than 3 times longer than average. Such situation meant an extreme instability of the atmospheric circulation, which hasn't been observed for the whole previous period; 2) since 1998 the 


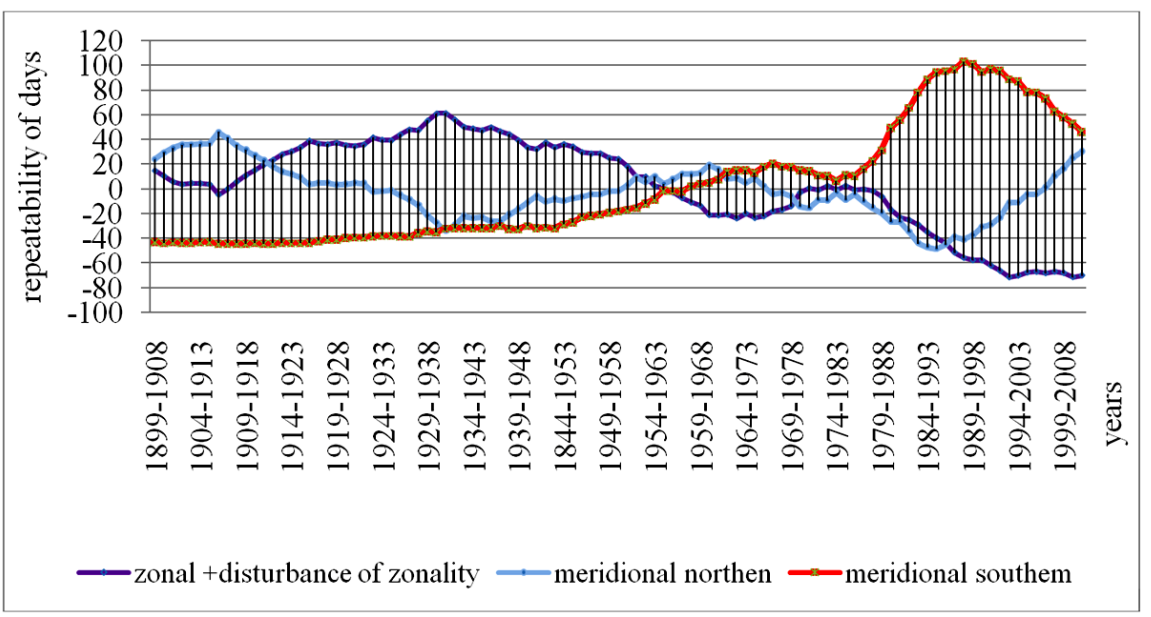

Figure 1. Deviations of the total annual duration of the generalized zonal group from their long-term average values for the period of 1899-2010 (10-year sliding averages).

duration of southern meridional processes started to decrease, and northern ones-to grow. In 2010 the total annual duration of northern meridional processes was 196 days, and meridional southern ones - 77 days.

\section{The Dependence of Runoff from Changes of Circulation Processes in the Earth's Atmosphere by B.L. Dzerdzeyevskiy}

In this study, experiments to confirm the hypothesis of the Professor Abay Tursunov about the dependence of runoff from changes of circulation processes in the Earth's atmosphere by B.L. Dzerdzeyevskiy are being conducted.

Out of 41 types of ECM we selected only those types of ECM, which, as it was presented, cause inflow of moist air to the south-west of Central Asia, form accumulation of precipitate and precipitation, and, as a result, affect the runoff, they are called "runoff-forming" ECM.

The certain areas were considered in this work: the Ile-Balkash basin, basin of rivers Shu-Talas and basin of the Syrdariya river, each basin is considered separately, since the runoff varies by regions and by the value of fluctuations, it is not permanent, because of the various factors of runoff formation in individual basins of that region (Figure 2).

\section{The Dependence of Runoff from Changes of Circulation Processes in the Earth's Atmosphere by B.L. Dzerdzeyevskiy in the Basin of Ile-Balkash}

The first object of the research were the left-bank tributaries of Ile river, as this area is the least affected by economic activity of the Ile-Balkash basin. Preliminary estimations to restore the runoff at individual posts were conducted earlier and the calculation of the main hydrological characteristics of the renewable water resources of the whole basin of the Ile river was made [11].

At the first stage an attempt to select various options of runoff forming ECM was made, dynamic schemes, annual and multi-year course of duration of effect (in days) of each type were carefully considered, and also an analysis of the literature sources in which an association of certain ECM with various natural phenomena was revealed. Calculations were made for the whole period of observation for the left bank tributaries of the Ile river from 1937 to 2000. In the Table 1 all types of ECM, used in these options of selection, were presented. Calculations for determining the correlation coefficients were consolidated in Table 2, Table 3.

Determination of runoff forming types of ECM for the whole basin of the Ile river was made after careful analysis and study of each individual type of ECM: dynamic scheme Figure 3 shows an example of one type of ECM.

It should be noted that all options included the 13-th types of ECM as the total duration of their effect in days for a year is the longest, compared to other types, and a long-term variability is characterized by a sharp increase 


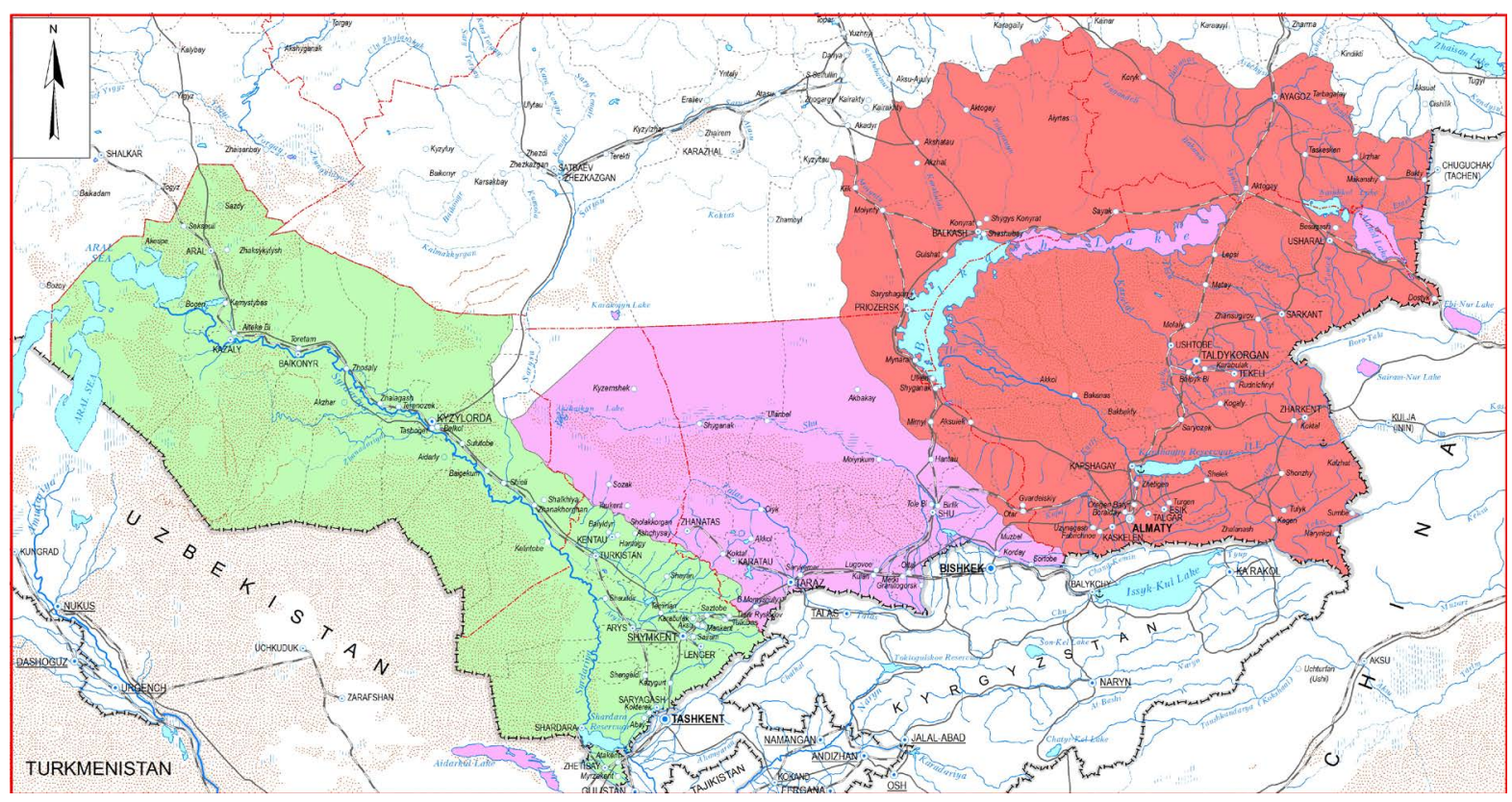

Figure 2. Hydrographic scheme of river basins of South Kazakhstan.

Table 1. Types of ECM considered in the course of the experiment.

\begin{tabular}{|c|c|c|}
\hline Option & Number of types & Types of ECM \\
\hline 1 (1937-2000), 6 (1975-2000) & 2 & $131,13 z$ \\
\hline 2 (1937-2000), 7 (1975-2000) & 22 & $\begin{array}{c}\text { 5a, 5b, 5v, 5g, 6, 7az, 7bz, 8a, 8bz, 8gz, 8gl, 9a, 9b, } \\
\text { 11a, 11b, 11v, 11g, 12bz, 12vz, 12g, 13z, 13l }\end{array}$ \\
\hline 3 (1937-2000), 8 (1975-2000) & 20 & $\begin{array}{l}\text { 1a, 1b, 5a, 5b, 5v, 5g, 7az, 7bz, 8a, 8bz, 8vz, 8gz, } \\
\text { 11a, 11b, 11v, 12g, 12vz, 12bz, 13z, 13l }\end{array}$ \\
\hline 4 (1937-2000), 9 (1975-2000) & 11 & 7az, 7bz, 8bz, 8vz, 8gz, 11g, 11v, 12bz, 12vz, 13z, $13 \mathrm{l}$ \\
\hline 5 (1937-2000), 10 (1975-2000) & 13 & 4b, 7az, 8a, 9a, 10a, 11a, 11b, 12a, 12bz, 12vz, 12g, 13z, 13l \\
\hline $11(1975-2000)$ & 5 & 4a, 4b, 8bz, 13z, $13 \mathrm{l}$ \\
\hline $12(1975-2000)$ & 8 & 8vz, 8vl, 8gz, 8gl, 10a, 10b, 13z, 13l \\
\hline $13(1975-2000)$ & 8 & 1b, 2v, 11g, 12a, 12bl, 12bl, 13z, $13 \mathrm{l}$ \\
\hline
\end{tabular}

Table 2. Coefficients of correlation of connection with of water runoff of the left bank tributaries of the Ile river and the sum of repeatability of various options of ECM (1937-2000).

\begin{tabular}{|c|c|c|c|c|c|c|c|c|c|c|c|}
\hline \multirow{2}{*}{$\begin{array}{c}\text { Option of } \\
\text { grouping of ECM }\end{array}$} & \multicolumn{11}{|c|}{$\frac{\Delta \tau}{r}$} \\
\hline & 0 & 1 & 2 & 3 & 4 & 5 & 6 & 7 & 8 & 9 & 10 \\
\hline 1 & 0.46 & 0.5 & 0.5 & 0.44 & 0.39 & 0.32 & 0.25 & 0.16 & 0.09 & 0.04 & -0.1 \\
\hline 2 & 0.57 & 0.55 & 0.54 & 0.51 & 0.45 & 0.39 & 0.33 & 0.27 & 0.21 & 0.13 & 0.03 \\
\hline 3 & 0.63 & 0.63 & 0.61 & 0.58 & 0.53 & 0.46 & 0.38 & 0.32 & 0.23 & 0.12 & -0.01 \\
\hline 4 & 0.48 & 0.46 & 0.46 & 0.44 & 0.42 & 0.38 & 0.34 & 0.28 & 0.22 & 0.14 & 0.03 \\
\hline \multirow[t]{2}{*}{5} & 0.38 & 0.41 & 0.46 & 0.46 & 0.49 & 0.47 & 0.43 & 0.36 & 0.29 & 0.22 & 0.13 \\
\hline & \multicolumn{11}{|c|}{$\Delta \tau$ is the shear, in years. } \\
\hline
\end{tabular}

in the number of days. In 1998 the repeatability of ECM 131 was exactly 70 days 
Table 3. The coefficients of correlation of connection $r$ with the shear $\Delta \tau$ of the sum of runoff of water of left bank tributaries of the Ile river and the sum of repeatability of various options of ECM (1975-2000).

\begin{tabular}{|c|c|c|c|c|c|c|c|}
\hline \multirow{2}{*}{$\begin{array}{l}\text { Option of grouping of } \\
\text { ECM }\end{array}$} & \multicolumn{7}{|c|}{$\frac{\Delta \tau}{r}$} \\
\hline & 0 & 1 & 2 & 3 & 4 & 5 & 6 \\
\hline 7 & 0.89 & 0.89 & 0.87 & 0.81 & 0.73 & 0.66 & 0.60 \\
\hline 10 & 0.89 & 0.86 & 0.90 & 0.89 & 0.82 & 0.74 & 0.66 \\
\hline 13 & 0.83 & 0.87 & 0.89 & 0.87 & 0.83 & 0.76 & 0.67 \\
\hline
\end{tabular}

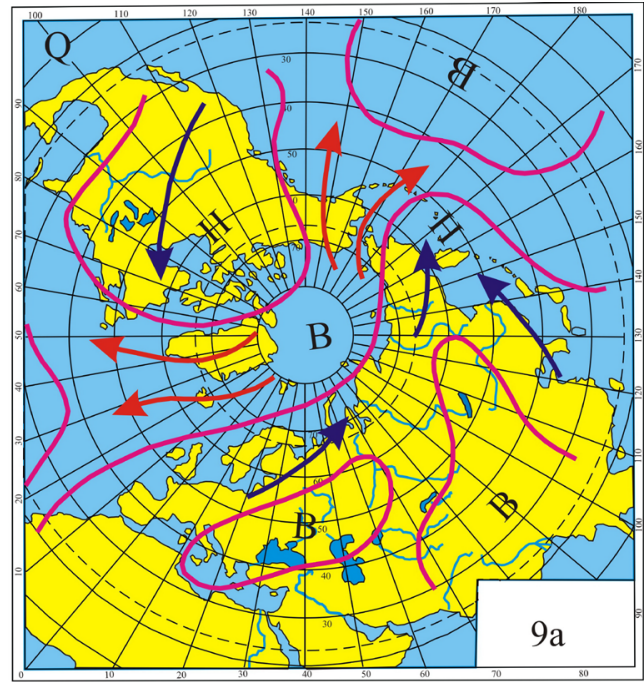

Figure 3. Dynamic scheme where red arrows are the movement of anticyclones, and blue ones — of cyclones ECM 9a.

(www.atmospheric-circulation.ru). As for the repeatability of ECM 13z in 1999 it reached 136 days. In the analysis of changes of 13-th types of ECM, their transfer into types of 11 and 8, which were also included into options of selection, are observed.

Study of dynamic schemes of types of 4, 5, 12 revealed that they cause the direct inflow of moist air exactly to the territory of Central Asia. As long as types of 2, 3, 6, some of the 1 and 10-th types are practically not active and little manifested in the annual course of the entire period of observation, they were not included into the major collections of options of ECM groups.

As a result of calculations a conclusion can be done that the comparison of repeatability of ECM and values of runoff of rivers of left bank tributaries of the Ile river for the entire period of instrumental observations (1937-2000) are slightly dependent on each other: Table 2 shows that correlation coefficients for this period are obtained as relatively small, maximum values do not exceed 0.48 - 0.63 .

Further the analysis was restricted only to the transgressive period of observation over the river runoff of the left-bank tributaries of the Ile river (1975-2000). Additional types of ECM, which gave the best results, were selected for comparison, and also three variants of groupings of types, options 11-13 ECM (Table 1). Study of dynamic schemes of additional types of 4, 5, 8, 12 revealed that these types of ECM cause the direct inflow of moist air to the territory of Central Asia and, therefore, influence precipitation and runoff; moreover the duration of effects of these types in days increases in the last decade. The conducted researches show that comparison of indices of circulation of B.L. Dzerdzeyevskiy with river runoff is possible only with joint grouping of ECM, i.e. there group influence take place.

According to the obtained sums of repeatability of days of ECM for the analysis 5-year average-outs were chosen and graphs of their long-term course, shown in Figure 4 were made. In order to identify the availability and closeness of relations between the selected types of ECM and runoff of the left bank tributaries of the Ile 


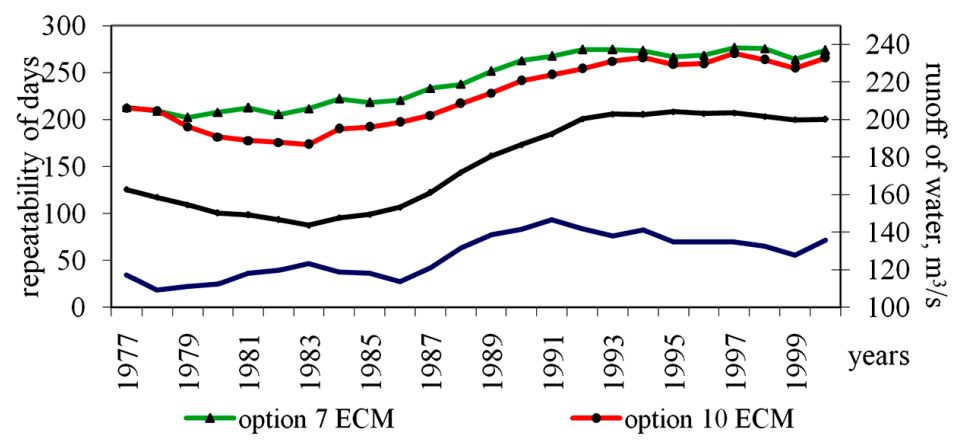

Figure 4. Progress of 5-year sliding: runoff of water of the left bank tributaries of the Ile river and total annual duration of ECM in days.

river the coefficients of correlation with the same shear of $\Delta \tau$ were calculated; the results are put in Table 3.

Table 3 shows that the maximum values of the correlation coefficient range from 0.89 to 0.90, i.e. we can speak of an availability of a good connection between the runoff of left bank tributaries of the Ile river and the selected types of ECM. The highest correlation coefficients are obtained in the option (10) with the shear of 2 and 3 years, in option (7) with the shear of 1 year and in option (13) with the shear of 2 years. Calculations of coefficients were made on 5-year average-outs both for runoff and for duration (total days) of ECM.

Thus, a direct impact of ECM on the river runoff was revealed, that previously was expressed as a hypothesis based on general considerations; and also the data on water inflow to the zone of runoff formation of the left bank tributaries of the Ile river were considered. The calculated values of coefficients of correlation of connection range from 0.60 to 0.90 (for the period from 1975 to 2000), that indicates the availability of a good connection between runoff of water of the tributaries of the Ile river and the selected types of ECM.

\section{The Dependence of Runoff from Changes of Circulation Processes in the Earth's Atmosphere by B.L. Dzerdzeyevskiy in the Basin of the Syrdariya River}

The next considered basin of South Kazakhstan: it is a basin of the Syrdariya river. Here some features that allow selecting specific types of ECM for their grouping with each other, i.e. runoff-forming ECM, were identified. Type of ECM $4 \mathrm{v}$ cause inflow of cold air on the territory of Kazakhstan which follows from the consideration of its dynamic scheme (www.atmospheric-circulation.ru). In aggregate, the duration of effect of types of 131 and $13 z$ reach significant values, starting since 1984: thus in 1989-201 days, 1997-179 days, 2000-143 days. Starting from 1980-ies an increase in the duration of effect of types of 9a, 12vz, 6, 11-th types were observed.

The certain options of groupings of ECM with summing up of their repeatability for the entire period of observations from 1899 to 2006 were calculated, and also a 5-year averaging of all considered values was made. 12 options of connection were calculated. Runoff in river basins of the basin of the Syrdariya river was estimated in the assessment of water resources for the period from 1928 and earlier till 2004. Some of the options of selection of groups of ECM are shown in Table 4, for all rivers of the basin of the Syrdariya river same groupings of ECM were taken.

Coefficients of correlation of connection of circulation processes in the atmosphere with rivers runoff range from -0.74 to 0.5 for the period of 1928-2004, and their higher rates of 0.96 -are revealed for the period of 1980-2004. For the basin of the Arys river the coefficients of connection are considerably lower than for the basin of the Keles river. For the basin of the Keles river the higher correlation coefficients of 0.96 are found for the period of 1980-2004 (Table 5). Coefficients of correlation of connection of ECM groups and runoff in the basin of the Arys river in most variants of calculations for the detection of connection did not give positive results, i.e. the highest connection coefficients are 0.68 .

Thus, analyzing the results of calculations (Figure 5, Table 4), performed for all options of communication both for the basin of river Keles and for the basin of river Arys it can be possible to make the following conclusions: for the period from 1928 to 2004 only a visual connection is observed, and for the period from 1980 to 2004 also a quantitative connection of indices of circulation by typification of B.L. Dzerdzeyevskiy with runoff of the zone of formation in the basins of rivers Arys and Keles. 
Table 4. Coefficient of correlation of connection of ECM groups and runoff in the basin of river Syrdariya.

\begin{tabular}{cccccccc}
\hline & \multicolumn{3}{c}{ Kazaly, 181 km from the mouth } & \multicolumn{3}{c}{ City/Station Kokbulak } \\
\cline { 2 - 8 } Options & 1911-2004 & $1950-2004$ & $1970-2004$ & $1980-2004$ & $\begin{array}{c}1970-2004 \text { without } \\
\text { averaging }\end{array}$ & $\begin{array}{c}\text { 1970-2004 with } \\
\text { 5-th averaging }\end{array}$ & $1980-2004$ \\
\hline & 0.52 & -0.16 & -0.23 & -0.27 & -0.19 & -0.40 & -0.25 \\
2 & -0.74 & -0.53 & 0.30 & $\mathbf{0 . 8 5}$ & 0.54 & $\mathbf{0 . 8 7}$ & $\mathbf{0 . 8 6}$ \\
3 & -0.16 & -0.41 & 0.51 & $\mathbf{0 . 9 0}$ & 0.43 & $\mathbf{0 . 8 6}$ & $\mathbf{0 . 9 0}$ \\
4 & -0.68 & -0.46 & 0.37 & $\mathbf{0 . 8 5}$ & 0.63 & $\mathbf{0 . 9 1}$ & $\mathbf{0 . 9 0}$ \\
\hline
\end{tabular}

Table 5. Groupings of ECM types by Dzerdzeyevskiy for the basin of Syrdariya river and coefficients of correlation of connection of ECM groups and runoff in the basin of Keles river, connection is satisfactory.

\begin{tabular}{|c|c|c|c|c|c|}
\hline Options & ECM types, included in the group & $1931-2004$ & $1950-2004$ & $1970-2004$ & $1980-2004$ \\
\hline 1 & $4 \mathrm{v}, 8 \mathrm{gz}, 11 \mathrm{a}, 11 \mathrm{~g}$ & 0.10 & -0.20 & -0.42 & -0.28 \\
\hline 2 & $4 \mathrm{v}, 9 \mathrm{a}, 12 \mathrm{a}, 13 \mathrm{l}, 13 \mathrm{z}$ & -0.19 & -0.05 & 0.72 & 0.96 \\
\hline 3 & 8gz, 11g, 11a, 12bz, 13z & -0.23 & 0.05 & 0.64 & 0.96 \\
\hline 4 & 6, 9a, 12a, 13l & -0.12 & -0.04 & 0.70 & 0.87 \\
\hline
\end{tabular}

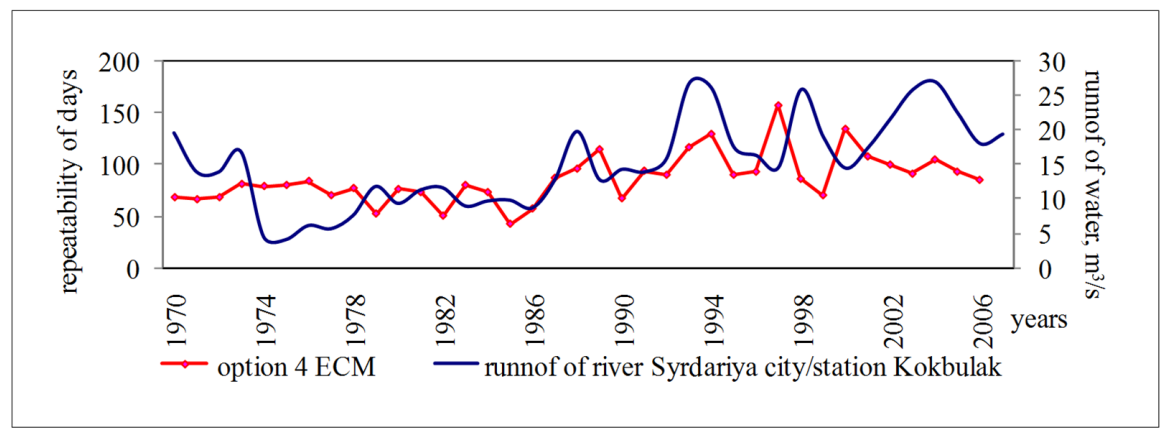

Figure 5. The graphs of connection of total annual duration (in days) of ECM and annual water expenditure for the basin of Syrdariya river.

Also an experiment to detect the connection of ECM groups with runoff outside the zone of runoff formation was conducted in this research, and downstream the Syrdariya river in the station in $181 \mathrm{~km}$ from the mouth, cities of Kazaly and Kokbulak, i.e. in the over-regulated by the reservoir zone (Table 4). Results of calculations of Table 4 show, that distribution of correlation coefficients for the same options of ECM groupings gave better results compared to the results, obtained in the basins of Arys and Keles rivers.

With calculation according to option 1 the lowest correlation coefficients are observed, which can be seen on all the tables. We consider this is due to the lack of ECM groupings of $13 \mathrm{l}$ or $13 \mathrm{z}$ types in the option 1, the duration of effect of which for the last 50 years considerably increased. However, the results are more optimistic according to other options of calculations, which can be seen from Table 4 for all rivers and stations. Particularly the correlation coefficients are high in options 3 and 4, where such types as 6, 9a, 11-e and $13 \mathrm{l}$ and 13z are included into the grouping.

Based on the analysis of the results of calculations (Figure 5, Table 4, Table 5), designed graphs of connection of runoff and ECM groupings for all options of river basins, the following conclusions can be done: from the period from 1928 to 2004 a visual connection is still observed, and for the period from 1980 to 2004 also a quantitative connection of atmospheric circulation by typification of B.L. Dzerdzeyevskiy with the runoff of the zone of formation in the basins of Keles and Arys rivers, as well as on Syrdariya river, is found.

From the experience of the previously conducted researches and from the present work it is found that with the shear of the runoff for 2 - 5 years relative to ECM the higher coefficients of connection are obtained. It is assumed that the good impact of circulation processes on the change of the runoff occurs within 2 - 5 years, i.e. delays for 3 years on the average. 


\section{The Dependence of Runoff from Changes of Circulation Processes in the Earth's Atmosphere by B.L. Dzerdzeyevskiy in the Basin of Shu and Talas Rivers}

Also in these researches a task of finding of a possible connection between the value of runoff for the basins of Shu and Talas rivers and the total annual duration of ECM (in days) was set. Water resources, i.e. runoff of the zone of formation of basins of Shu and Talas rivers were defined by traditional methods, adopted in hydrology. In addition to the data on the river runoff on the territory of Kazakhstan the data on hydrostations, located on the territory of Kyrgyzstan, are used.

Using the same techniques as for the considered above basins, works on groupings of ECM options for the basins of Shy and Talas rivers were carried out. In Table 6 some options for selecting ECM groups are presented. Figure 5 shows graphs of the joint course of ECM options and runoff.

Some individual ECM groupings were calculated with summing of their repeatability for the whole period of observations from 1900 to 2006. In this case the calculations on 5-year averaging of the total duration of all ECM groups, as well as on the runoff of Shu and Talas rivers, were made, which was used in the previously conducted researches. 15 options of connection were calculated. In the assessment of water resources the runoff in basins of Shu and Talas rivers was calculated for the period since 1930 and earlier, however the reliable series of water expenditure for many observation stations were not obtained, therefore we limited ourselves to the period from 1950 to 2002.

Coefficients of correlation of connection of circulation processes in the atmosphere with the rivers runoff range from -0.64 to 0.2 for the period from 1950-2002, and their higher rates are again found in the period of 1980-2002 0.01 - 0.26. For the basin of river Shu, the obtained connection coefficients are considerably lower, than for the basin of the Talas river. With the shear of the series of runoff relative to ECM for 2 - 5 years for the period of observations from 1950 to 2002 sufficiently good $(0.7-0.9)$ the connection coefficients were not available. It is assumed, that the influence of circulation processes on the change of characteristics of runoff again occurs within 2 - 5 years, i.e. is delayed by an average of 3 years.

For the basin of river Talas the coefficients of correlation of connection range from -0.4 to 0.002 for the period of 1950-2002, higher coefficients of correlation are found in the period from 1980-2002, and they are

Table 6. Groupings of ECM types by B.L. Dzerdzeyevskiy for the basins of Shu and Talas rivers.

\begin{tabular}{|c|c|}
\hline Options of groupings & ECM types, included in the group \\
\hline 1 & $131,13 z$ \\
\hline 2 & $4 \mathrm{a}, 4 \mathrm{v}, 8 \mathrm{bz}, 13 \mathrm{z}, 13 \mathrm{l}$ \\
\hline 3 & $4 \mathrm{v}, 9 \mathrm{a}, 12 \mathrm{a}, 13 \mathrm{l}, 13 \mathrm{z}$ \\
\hline 4 & 7az, 7bz, 8bz, 8vz, 8gz, 11g, 11v, 12bz, 12vz, 13z, $13 \mathrm{l}$ \\
\hline 5 & 4b, 7az, 8a, 9a, 10a, 11a, 11b, 12a, 12bz, 12vz, 12g, 13z, $13 \mathrm{l}$ \\
\hline 6 & 8vz, 8vl, 8gz, 8gl, 10a, 10b, 13z, $13 \mathrm{l}$ \\
\hline 7 & $1 \mathrm{~b}, 2 \mathrm{v}, 11 \mathrm{~g}, 12 \mathrm{a}, 12 \mathrm{bl}, 12 \mathrm{vl}, 13 \mathrm{z}, 13 \mathrm{l}$ \\
\hline
\end{tabular}

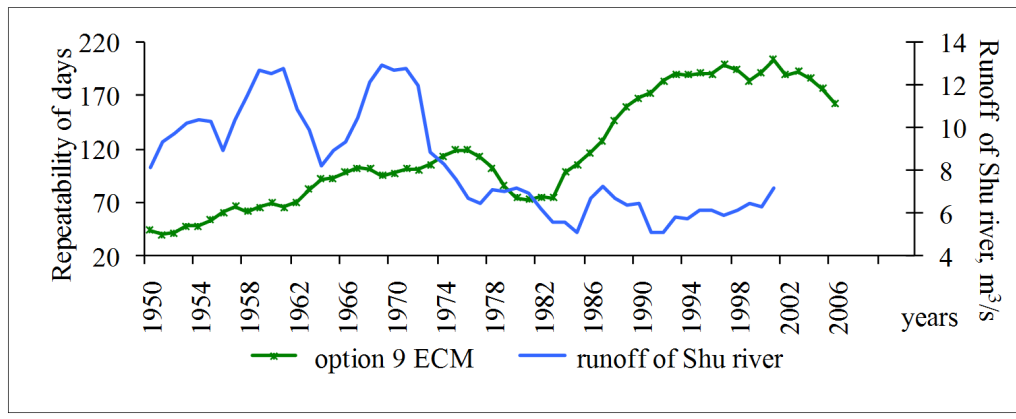

Figure 6. Graphs of connection of 5-year average-outs of total annual duration of ECM and annual expenditure of water for the basin of Shu and Talas rivers. 
good enough: 0.81 - 0.91 .

Thus, based on the results of calculations (Figure 6) designed for 15 options of connection both for the basin of Shu river and the basin of Talas river the following conclusions can be done: for the period from 1950 to 2002 only visual connection is observed, and for the period from 1980 to 2002 also a quantitative connection of the indices of circulation on typification by Dzerdzeyevskiy with the runoff of zone of formation in the basins of rivers Shu and Talas is found.

\section{Conclusions}

The obtained results are not very satisfactory and the further search of options of groups and analysis of ECM types will possibly allow revealing a closer connection between runoff of the Shu and Talas rivers and ECM by Dzerdzeyevskiy.

Thus, analyzing the results of calculations, obtained for all basins of rivers of South Kazakhstan the following conclusions can be done:

1) For some basins a relation between runoff and options of ECM for the period of observations from 1930 to 2006 is missing, but there is a visual connection; however a close and quantitative relation of indices of circulation by typification of Dzerdzeyevskiy with the runoff of zone of formation in basins of major rivers for the period from 1980 to 2006 is found.

2) It was found from the conducted researches on all river basins of South Kazakhstan that with the shear of runoff relative to the course of ECM options for 2 - 5 years there are higher coefficients of connection, which show the influence of circulation processes on the change of characteristics of runoff, and this occurs within 2 5 years, i.e. it is delayed on an average of 3 years.

3) In addition, as it was mentioned earlier, types of circulation by B.L. Dzerdzeyevskiy characterize the situation of the whole northern hemisphere of the planet, and in this paper a small area of south-eastern Kazakhstan was selected for the experiment.

However, the calculations performed have shown the possibility of using typification of ECM for further researches of climatic changes, including determining the direction of change of river runoff in other river basins. The created database on annual values of each of the 41 types of ECM can be used in other studies as well.

\section{References}

[1] Mitchell, J.M., Dzerdzeevskii, B., et al. (1966) Climatic Change. World Meteorological Organization, Geneva.

[2] Dzerdzeyevskiy, B.L. (1968) Circulation Mechanisms in the Atmosphere of Norhern Hemisphere in XX Century. Inter-Departm. Geophys. Committee of the AS of the USSR: Procedings of met. researches. - M., - p. 240. (In Russian)

[3] Dzerdzeyevskiy, B.L. (1975) General Circulation of the Atmosphere and Climate. Selected Works, -M. (in Russian)

[4] Barry, R.G. and Perry, A.H. (1973) Synoptic Climatology Methods and Applications. Methuen \& Co Ltd., London, 555 p.

[5] Calendar of the Consistent Change of ECM for 87-Year Period (from 1899 to 1985) (1987) //Inter-Departm. Geophys. Committee of the AS of the USSR, Proceedings of Meteorological Researches. - № 13, 29-116. (In Russian)

[6] Savina, S.S. and Khmelevskaya, L.V. Elementary Circulation Mechanisms the Northern Hemisphere (by) (1998) Resources and Environment World Atlas in Two Volumes. Russian Academy of Sciences. Institute of Geography. Austrian Institute of EAST and Southeast European Studies. Vienna. Published by ed. Holsel, Vienna, Volume I, 50-51.

[7] Zolotokrylin, A.N. and Khmelevskaya, L.V. (1999) Atmospheric Circulation and Precipitation in the Aral Basin in the Current Century.//Newsletter of the AS, Series of geograph. Natural processes and Dynamics of Geosystems,. -M.: № 5, 30-33. (In Russian)

[8] Institute of Geography of the Russian Academy of Sciences www.atmospheric-circulation.ru RFFI 08-05-00475-a

[9] Akhmetova, G.S. (2001) The Role of Circulation Conditions in the Atmosphere in the Change of Temperature of Air over Northern Hemisphere for the Period from 1899 to 1987. /Geography in Kazakhstan: Results and Ways of Development: Collection of Proceedings of the Conference. - Almaty: «Gylym», 97-101. (In Russian)

[10] Eriskovskaya, L.A. (2005) Meteorological Dependence of Fluctuations of the Border of Feeding on the Tuyuksu Glacier. Hydrometeorology and Ecology, 2, 79-88. (In Russian)

[11] Tursunov, A.A. and Ais, T. (2005) Climate-Driven Changes of Runoff of Mountain Rivers of Basin of Balkhash Lake. Scientific and Technical News of STU of St. Petersburg, Proceedings of the International Scientific-Theoretical Conference Dedicated to the 100-the Anniversary of R.R. Chugayev, No. 1, Publishing House of the Polytechnic University, 
St. Petersburg, 72-75. (In Russian)

[12] Byshev, V.I., Kononova, N.K., Neiman, V.G. and Romanov, Yu.A. (2002) Peculiarities of the Climate Dynamics in the Northern Hemisphere in the 20th Century. Doklady Earth Sciences, 385, 538-545.

[13] Kitaev, L.M., Krenke, A.N. and Titkova, T.B. (2005) Climatic Limits of Snow Storage Increase over Northern Eurasia. Ice and Climate News, Lundblad Media, Troms, No. 6, 14-15.

[14] Ananicheva, M. and Kononova, N. (2006) Climate Fluctuation: Consequences in Weather Change and Human Health for Moscow Region and Kamchatka Region. International Geographical Union, IGU 2006 Brisbane Conference and Joint Meeting of the Institute of Australian Geographers and the New Zealand Geographical Society Conference Logo Produced by Geographics Unit, School of Geography and Environmental Science, The University of Auckland, 3-7 July 2006, Regional Responses to Global Changes, a View from the Antipodes, 5.

[15] Chernavskaya, M.M., Kononova, N.K. and Val'chuk, T.E. (2006) Correlation between Atmospheric Circulation Processes over the Northern Hemisphere and Parameter of Solar Variability during 1899-2003. Advances in Space Research (JASR), 37, 1640-1645.

[16] Matskovskiy, V.V. and Kononova, N.K. (2011) Study of Fluctuations of Circulation of Atmosphere of the Northern Hemisphere by the Method of Digital Mapping. Izvestiya of the RAS, Geographic Series, No. 6, 100-114. (In Russian)

[17] Kononova, N. (2013) Northern Hemisphere Atmospheric Circulation According to Classification by B.L. Dzerdzeevskii. Abstract Proceedings, Davos Atmosphere and Cryosphere Assembly DACA-13, Davos, 8-12 July 2013, 337. 